\title{
Establishing the Writing Centre at Valsayn
}

\section{Campus, UTT}

\section{Barbara Constance and Nicaise Joseph}

\begin{abstract}
More nationals of Trinidad and Tobago are accessing tertiary education annually. In most instances, they are required to complete a foundations course in English Language. However, many students enter colleges and universities with severe writing deficiencies, often stemming from a deeply ingrained lack of confidence and competence in English as a Foreign Language. To address these deficiencies, The University of Trinidad and Tobago (UTT) established the Writing Centre at the Valsayn Campus, where students can meet with a tutor to help them improve their writing. This paper traces the development of the Writing Centre at Valsayn and addresses the question of whether or not a writing centre can improve students' writing ability. While formal research must still be engaged in, the paper highlights that the writing centre is a valuable support to the teaching and learning done in language and writing courses.
\end{abstract}

Keywords - Writing Centre, UTT, Official Language, Pedagogy

\section{INTRODUCTION}

The University of Trinidad and Tobago's (UTT) Centre for Education Programmes (CEP) became responsible for the training of teachers in 2006 after the Teachers' College system was discontinued that same year. As a result, while student teachers would usually have had two years of training to earn a teacher's diploma, they were now entering into a four-year system at the end of which they would earn a Bachelor of Education (B.Ed.) degree. However, in as much as this would have meant exiting the training with higher qualifications, the entry requirements into the B.Ed. were similar to those of the diploma programme. This means that students were not required to have more than the standard five Caribbean Examination Council (CXC) Caribbean Secondary Education Certificate (CSEC) passes (including English A, Mathematics and a Science subject) to gain entry into the B.Ed. programme. These students are allowed entry with passes ranging from a grade one to a grade three, including in the subject of English A.

As such, students enter tertiary level education with varying levels of challenges in the speaking and writing of Standard English, the official language of Trinidad and Tobago and the language of academia. One of the prevailing reasons is that the students come from a background in which Trinidad and/or Tobago Creole is the native language. This poses certain problems for written assignments and teaching practice, especially for students who are training to be teachers, who are required to be competent in the speaking and writing of Standard English. Not only does this teacher have to master the use of Standard English but also be prepared to teach in this multilingual, cosmopolitan society.

The teacher is also required to be the model of language speaking and writing for the students. This is particularly necessary in a society where the use of the target language, Standard English, may only ever be heard spoken in a live setting when students are in the classroom. Thus, when the teacher uses the target language in the classroom, students would be more inclined toview it as a viable and useful option (Littlewood \& Yu, 2011), thus leading them to pay attention to the language and pattern after it consciously and sub-consciously. In addition to the speaking of the target language is the fact that the student teachers themselves are practising to teach students the use and structure of Standard English. This usually entails the students spending much of the class time in writing in the numerous Language Arts subjects. However, the same teachers who are required to have this speaking and writing competence generally themselves have struggles with the some of the skills. This is a perennial issue with Solomon (1993) highlighting that "primary school teachers' knowledge of the standard was, is, and is likely for a long time to remain, more restricted than they think" (p. 188).

Many of the students at the CEP, Valsayn Campus enter the University with the common Standard English usage challenges as they pertain to the required grammatical, mechanical and structural skills. This is exacerbated upon entering the tertiary level of studies, because a major skill required for every course is writing, whether expository, 
reflective or argumentative, and for each mode, a number of sub skills and methods are needed. As reported by Tan et al (2006), "[W]riting in English requires a culmination of multiple abilities such as linguistic, cognitive, rhetorical and social skills, in addition to positive attitudes to writing" (p. 10). It is not always possible to give these skills the depth of attention which is usually required by the greater percentage of the students, especially in a society where Standard English is the second language of most citizens. To address this need, the then programme leader of the Valsayn Campus took the decision to establish a Writing Centre, which, according to Tan et al., is of itself also an approach to addressing writing issues. At the Valsayn Campus, this centre was established in 2011 to ensure that students were given the additional assistance needed without having to source external tutors, which could incur an additional expense for the University.

The situation of having a Writing Centre is not unique to the UTT or even to other tertiary institutions in Trinidad and Tobago. As many as one thousand writing centres had been established, since the concept was developed, between the $20^{\text {th }}$ Century and 2004 in North America (Harris, 2004, as cited in Hoon, 2009). Thus, even countries that are regarded as having English as their first language encounter students who struggle with varying aspects of writing. This struggle is also prevalent in the United Kingdom as submitted by Yeats, Wheeler, Reddy and Senior (2011). They posited that contemporary students are not displaying a high level of proficiency in academic writing. Furthermore, they claimed that "despite the weight attached to academic writing, it appears that mastery of it is at an insufficient level in many institutions" (p. 500).

Despite the weight attached to academic writing, it appears that mastery of it is at an insufficient level in many institutions.

It is, thus, understandable that countries such as Trinidad and Tobago, for which Standard English is a second language, would embark upon the task of establishing writing centres, more so at the tertiary level, which produces the highest number of students for the professional market. Based on Pragg's (2014) assessment, "this heightened interest in higher education [within the Caribbean region] can be understood as either a consequence of or a catalyst for the employers' heavy demand for persons with post-secondary qualification" (p. 66).Added to this is the fact that employers are especially interested in employees who are proficient in writing and reporting skills (Yeats, Wheeler, Reddy \& Senior, 2011).
Establishing a writing centre has been the direction many universities have taken to address the problem of writing weakness, in spite of there being writing courses offered. However, the progress of the writing centres has not been actively measured. Yeats, Wheeler, Reddy, Senior and Murray (2011) asserted that "A number of universities have introduced writing centres aimed at addressing this problem; however, the evaluation of such centres is usually qualitative" (p. 499).This includes the UTT, because even though the students are given a diagnostic test at the beginning and a post-test at the end, there is no formal ongoing quantitative research in place to measure the progress. Evaluation is usually through comparing students' writing, observation and oral feedback to the diagnostic test that is done at the beginning of their tenure.

\section{LITERATURE REVIEW}

\section{Purpose of the Writing Centre}

Different views and reasons for having a writing centre have been cited by authors who have been directly involved in the development and implementation of the writing centre. For most, the common aim is to support students with a view to improve their writing. This is expressed by Clarence (2011) who states that, "The Writing Centre, as it is at present, aims to support students with their writing task, in order to help them produce work of an acceptable standard by assisting them with decoding and making sense of these academic conventions and assessment criteria" (p. 103). This suggests that students may not always grasp all the nuances of academic writing in the larger setting of the lecture, warranting a more individualistic mentoring. Furthermore, it connotes that students may be required to have a designated space wherein they can focus on the practising their writing while being supported.

The idea that the writing centre is useful in providing that personal tutoring is also supported by Rafoth (2010) who discusses the benefits of the conversational atmosphere that is fostered by the writing centre. He notes that since writing is so difficult to do alone, having someone with whom one can converse and express one's challenges, while being guided, is beneficial to the students. Nichols (2011) argues that writing centres "offer an alternative to the belief that knowledge is handed down from master to disciple; in fact they can galvanize the disciples to talk back to the masters." (p. 85). The social context of writing centres fosters a relaxing atmosphere along with individualised tutoring which encourages and enables the students to be 
inclined to focus on their writing and more open to understanding the conventions of writing.

According to Harris, "Working in the context of a writing center means that the tutor has easy access to the director, to a support group of other tutors, to materials and resources, and to meetings where tutors can ask for help in solving problems" (p. 111). Based on this philosophy, the particular university is engaged in employing part-time tutors to fill in the gaps and struggles that students may face to complement the primary lecturer's tutoring. However, this tutor would be working closely with the coordinator and other fellow tutors. This would serve to ensure that the tutors are like minded and are able to share pedagogical approaches that are innovative and successful. In terms of the ready access to materials and resources, the writing centre should provide as many and as wide a range of instruments that could be used by writers with different strengths and talents. These could include writing pads, tablets, computers, charts, sample essays, worksheets, whiteboards and grammar and writing texts.

Archer and Parker (2016) submitted that "Writing centres are spaces that suspend daily life in order to engage with ideas, prompt new ways of seeing and provide opportunities for reflection" (p. 43). This perspective has been reflected in the Writing Centre at the UTT, which is situated in a separate block from those wherein classes are held. This allows the necessary privacy that students seek as they attempt to address their deficiencies. Furthermore, the sessions are held in a writing environment that is rich in literature and writing resources. Also, the students are given small group and individual attention where they could engage in discussions and internal reflection.

\section{Pedagogical Approaches}

According to Harris (1995), one of the major pedagogical approaches to tutoring in a writing centre is being able to have contact with students on a one-on-one basis. In this way, the tutor is able to interact with the students and diagnose the unique linguistic problems that each student has. This allows the tutor to adjust the pedagogical approaches to suit the needs of the students. He further asserted that the tutor is more of a facilitator and acts as a coach or a collaborator who helps the student to improve his or her writing.

Another approach to teaching that has been used for instruction at the writing centre is the conversational approach. Busekrus (2018) purported that with the conversational approach instructors at the Writing Centre engage in discussing students' writing challenges instead of annotating their writing concerns. Thus, the conversational approach has the tendency to stimulate students to spend time reflecting more clearly and deeply, because conversation would spur on their critical thinking processes. This reflection can be enhanced by specific questions and guided suggestions by the writing instructor. The conversational interaction is also underscored by Wardle (2007) who argued that reasoning and discussion are necessary if instructors are to successfully transfer information to learners. This approach engenders instant feedback and analytical examination of the prevailing issues and how they can be resolved.

Busekrus (2018) further asserted that "Research has indicated that feedback that is intentional, specific, and reflective benefits students' writing growth and the transfer process" (p. 1). This is understandable, because this would allow students to receive explicit feedback on their writing issues and thus be more equipped to address them directly. The conversational approach fits into the philosophy espoused by the UTT Valsayn Campus Writing Centre which outlines that the centre should allow students the opportunity to meet with their instructors for consultations. The very nature of consultations necessitates the use of conversation.

Another view on how writing instruction or coaching should be approached is that of acceptance of the language variation of the students (Olson, 2013). In this approach, the author is proposing that writing done in the non-official language should not be viewed punitively. Instead, the writing should be seen as making an intellectual contribution to scholarship in the university. This ensures that students understand that though their mother tongue may not be the official language, it is still a valid means of communication that can be used successfully to transmit ideas. Olson (2013) referred to this as a strength-based approach. While this approach is commendable, it is not one that has been considered, far less embraced, in Trinidad and Tobago. English Language Arts teaching has generally been taught prescriptively, with the focus being on the teaching of Standard English rules, which generally differ from Trinidad and Tobago Creole grammar.

However, there is a case to be made as it relates to the bridging of culture and the acknowledgement of the cognitive contributions that are made by non-standard writers. In many instances, their ideas are never shared because they are unable to articulate these in the target language. One of the author's experiences in a Trinidad and Tobago English Language Arts classroom revealed that students who are allowed to freely express themselves in 
their mother tongue are more open to the teaching of Standard English. This activity was conducted across four second form classes with all classes showing a similar openness after having their home language recognised in an academic setting.

At the University of Trinidad and Tobago (UTT), the tutors of the writing centre actually meet with small groups and do whole class work with the particular groups and then segue into individual tutoring. The teaching strategies include questioning, demonstration, practice, viewing and reinforcement of previous knowledge. These instructors are all versed in pedagogical strategies in grammar and other language arts. They have also engaged in teaching practice and have taught Written Communication and Academic Research and Writing. Moreover, the Writing Centre offers an interactive environment, in which students can practise and improve their writing skills with immediate feedback from their instructors.

\section{CHOOSING STUDENTS FOR THE UTT WRITING CENTRE}

Because the writing centre sought to give students individual attention in spite of the high numbers of students needing assistance, a referral system was put in place. This consisted of lecturers identifying the students in their classes who were having difficulties with self-expression in written assignments. These students were then met by the tutor/s assigned to the writing centre and given a diagnostic test to determine their level of competence and need. However, because of the scarcity of available tutors only the cases that were considered most crucial were considered.

While all the students are required to do a foundation English class entitled "Written Communication", very few students can make significant strides in the improvement of their language in the space of one semester since some come to the university with deep language challenges with respect to the usage of Standard English. Additionally, the sheer size of these classes do not afford the individualized attention that would be necessary for some students to adequately correct their challenges.

The Writing Centre students are those who have been identified as having writing problems in certain courses and who have had problems attaining success in these programmes of study. The Writing Centre provides them with the opportunity to work in an environment which is geared solely towards writing practice. It also allows students to have more time to engage with writing tutors in a structured manner without having the large number of students present. This individualised instruction environment encourages a level of comfort that leads to more successful language acquisition with regard to writing at an academic level. Sessions are also conducted in a consultative manner whereby students can voice their goals, concerns, frustrations and progress. This also serves to make the writing centre more appealing and approachable, which, according to Brown's (2014) language ego principle, states that all second-language learners need to be treated with sensitivity, especially as "highly intelligent adults can be reduced to babbling infants in a second language" (p. 72).

\section{WRITING CENTRE DESIGN}

Writing Centres are designed in different ways depending on their foci. What is common to all are core materials such as dictionaries, grammar books, worksheets and style guides. At the UTT, other materials and resources include whiteboards, communal and individual desks, computers and online programmes. According to Harris (2004) and Waller (2002) (as cited in Hoon, 2009), "reference materials for their clientele such as guidebooks, dictionaries, thesauri, grammar references, style guides, encyclopaedias, worksheets on specific skills, and essay models" (p. 2) are essential tools.

Writing centres are usually equipped with computers and printers for writers to refine their drafts. While certain writing centres also provide snacks to create a more relaxing atmosphere (Harris, 2004; Waller, 2002 as cited in Hoon, 2009), the UTT's Writing Centre has not evolved to that stage since its students are only scheduled for one hour weekly as opposed to the open-door policy encouraged by some other universities.

\section{CONCLUSION}

The Writing Centre at UTT is an essential tutorial support system designed to improve students' overall competence and confidence in writing. While greater qualitative and quantitative data would need to be collected to attest to its efficacy in the future, anecdotal evidence highlights that students have benefitted from the individualized attention provided. Students have been moved to a position where they can self-correct and write with greater levels of efficiency. Greater marketing of the Writing Centre at orientation sessions and through the university's various social media platforms, as well as notice boards and from instructors should result in more students grasping the opportunities provided by the centre. 


\section{REFERENCES}

[1] Archer, A., \& Parker, S. (2016). Transitional and transformational spaces: Mentoring young academics through writing centres. Education as Change, 20(1), 43-58. https://dx.doi.org/10.17159/1947-9417/2016/567

[2] Busekrus, E. (2018). A conversational approach: Using writing centre pedagogy in commenting for transfer in the classroom. Journal of Response to Writing, 4(1): 100-116.

[3] Brown, H. D. (2016). Teaching by principles: An interactive approach to language pedagogy $\left(6^{\text {th }}\right.$ ed.). New Haven, CT: Yale University Press.

[4] Clarence, S. (2011). Writing in the academy: Collaborative writing development with students and lecturers at the UWC Writing Centre. Rhodes University.

[5] Harris M. (1992). The writing center and tutoring in WAC programs. In: SH McLeod \& M Soven (eds). Writing across the curriculum: A guide to developing programs. London: Sage. 154-170.

[6] Hoon, T. B. (2009). Assessing the efficacy of writing centres: A review of selected evaluation studies. Pertanika Journal of Social Sciences and Humanities, 17(2), 47-54.

[7] Littlewood, W., \& Yu, B. (2009). First language and target language in the foreign language classroom. Language Teaching - LANG TEACH. 42. DOI 10.1017/S0261444809990310.

[8] Nichols, Pam. (2011). A snowball in Africa with a chance of flourishing: Writing centres as shifters of power in a South African university. Current writing: Text and reception in $\begin{array}{llll}\text { South } & \text { Africa, } & 10 & \text { (2), }\end{array}$ https://doi.org/10.1080/1013929X.1998.9678044

[9] Olson, B. (2013). Re-orienting composition and writing center pedagogy: A strengths-based approach for multilingual writers (Doctoral dissertation). Retrieved from ProQuest.

[10] Pragg, K. (2014). Tertiary education and the direction for future research: Accommodating the shifting demographics of the Caribbean's tertiary student. Journal of the Department of Behavioural Sciences, 3(1), 65-80.

[11] Rafoth, B. (2010). Why visit your campus writing center. Writing spaces: Readings on writing, 1, 146-155.

[12] Solomon, D. (1993). The speech of Trinidad: A reference Grammar. St. Augustine: The University of the West Indies.

[13] Tan, B.H., Emerson, L., \& White, C. (2006). Reforming ESL writing instruction in tertiary education: The writing centre approach. The English Teacher, XXXV, 1 - 14.

[14] Wardle, E. (2007). Understanding 'Transfer' from FYC: Preliminary results of a longitudinal study.WPA 31.1/2,12449.

[15] Yeats, R., Reddy, P., Wheeler, A. \& Senior, C. \& Murray, J. (2010). What a difference a writing centre makes: A small scale study. Education and Training, 52, 499-507. Retrieved from DOI: 10.1108/00400911011068450. 